\section{A program to generate \\ Gellermann (pseudorandom) series of binary states}

\author{
RICHARD J. FRAGASZY \\ Department of Civil Engineering \\ University of California, Davis, California 95616 \\ and

D. MUNKENBECK FRAGASZY
Department of Psychology
University of California, Davis, California 95616

A FORTRAN computer program is described for the generation of pseudorandom series of binary states. The program utilizes a generalized set of logical properties derived from those originally developed for series of a specific length. The generalized statement of these properties allows the construction of series of any length.

This paper describes a FORTRAN IV computer program that generates "Gellermann" series (pseudorandom series of binary states; Gellermann, 1933) accoring to criteria specified by the user. Series of this type are frequently used in experimental designs in which one wishes to control for order of left-right placement or present-absent conditions (Hilgard, 1951, p. 533). Gellermann (1933, p. 207) proposed five criteria for adequately controlled series of length 10 :

" 1 . Each series must contain five rights and five lefts.

2. No series should have more than three rights or three lefts in succession.

3. At least two rights and two lefts must appear in both the first and last halves of each series.

4. Each series must contain only five reversals from right ot left or left to right.

5 . The series must offer a chance score of $50 \%$ correct from either single or double alternation of response."

We have developed a computer program in which these statements are generalized. The program repeatedly generates a random series of any length desired by the user (up to 40) and then tests it against specific values of the above criteria. The user specifies the acceptable range for each of Gellermann's criteria except the second. For example, the user enters the minimum and maximum numbers of agreements between the generated series and a single-alternation test

The Computer Center, University of California, Davis, provided funds for the computer work reported here. This work was supported by an NSF predoctoral fellowship to D. M. Fragaszy. series specified in the program. (Note: Gellermann's criteria for a "good" series are specific to series of length 10.) The generalizations of his criteria in this program permit inclusion of series of any length up to 40 , and allow relaxation on restriction of criteria to suit the user's needs. The following input variables define the task: (1) LS = length of series desired, (2) ITMAX = maximum number of iterations allowed, (3) NSW = number of unique series desired (a series is not counted if its mirror image has already been found), (4) RAND $=$ the seed for the pseudorandom number generator.

The general test statements follow Gellermann's original statements; our interpretations of Gellermann's criteria, extended to any series of length LS, are noted in parentheses after each general statement cited below. To change criteria values, change entered values of the allowable range of $\mathrm{N}, \mathrm{H}, \mathrm{R}$, and $\mathrm{C}$.

1."Each series must contain five rights and five lefts." NMIN $\leqslant \mathrm{N} \leqslant \mathrm{NMAX}$, where $\mathrm{N}=$ number of one state $(\mathrm{NMIN}=\mathrm{NMAX}=\mathrm{LS} / 2$ for even series; $\mathrm{NMIN}=$ $\mathrm{LS} / 2-.5, \mathrm{NMAX}=\mathrm{LS} / 2+.5$ for odd series).

2. "No series should have more than three rights or three lefts in succession." (Not generalized.)

3. "At least two rights and two lefts must appear in both the first and last halves of each series." $H M I N \leqslant H \leqslant H M A X$, where $H=$ number of one state in either half of the series. For odd series the middle value is not included in this test. (HMIN = HMAX = $\mathrm{LS} / 4$ for even series divisible by $4 ; \mathrm{HMIN}=\mathrm{LS} / 4-.5$, $\mathrm{HMAX}=\mathrm{LS} / 4+.5$ for all other series).

4. "Each series must contain only five reversals from right to left or left to right." $\mathrm{RMIN} \leqslant \mathrm{R} \leqslant \mathrm{RMAX}$, where $R=$ number of reversals from one state to the other $(\mathrm{RMIN}=\mathrm{LS} / 2-1, \mathrm{RMAX}=\mathrm{LS} / 2$ for even series; RMIN $=$ RMAX $=$ LS $/ 2-.5$ for odd series).

5. "The series must offer a chance score of $50 \%$ correct from either single or double alternation of response." (CMIN $\leqslant \mathrm{C} \leqslant \mathrm{CMAX}$, where $\mathrm{C}=$ the number of agreements between the series and single- and doublealternation test series, respectively.) $\mathrm{CMIN}=\mathrm{CMAX}=$ $\mathrm{LS} / 2$ for even series; $\mathrm{CMIN}=\mathrm{LS} / 2-.5, \mathrm{CMAX}=$ $\mathrm{LS} / 2+.5$ for odd series).

Using the explicit criteria stated above, it was difficult to find series of length 10 or 18 meeting Criterion 5 (agreements with single- and double-alternation test series). On closer inspection, Gellermann's original (1933) series produce a 40\%-60\% performance using a single-alternation strategy and a greater variation (up to $10 \%-90 \%$ ) using a double-alternation strategy. For example, two-thirds of the 48 series listed by Gellermann produce $30 \%-70 \%$ response accuracy if a doublealternation strategy is used. None met the stated criteria; the double-alternation tests were the sources of failure. For series of length 10, using a sliding series of criteria for agreement with alternation test series, 
Table 1

Summary of Information on Three Computer Runs Performed Per Series Length

\begin{tabular}{cccccc}
\hline $\begin{array}{c}\text { Series } \\
\text { Length }\end{array}$ & $\begin{array}{c}\text { Mean Number of } \\
\text { Iterations to Produce } \\
10^{*} \text { Unique Series }\end{array}$ & $\begin{array}{c}\text { Lefts } \\
\text { (NMIN/NMAX) }\end{array}$ & $\begin{array}{c}\text { Lefts in Either Half } \\
\text { (HMIN/HMAX) }\end{array}$ & $\begin{array}{c}\text { Reversals } \\
\text { (RMIN/RMAX) }\end{array}$ & $\begin{array}{c}\text { Agreements } \dagger \\
\text { (CMIN/CMAX) }\end{array}$ \\
\hline 10 & 5000 & $5 / 5$ & $2 / 3$ & $4 / 5$ & $4 / 6$ \\
12 & 5141 & $6 / 6$ & $3 / 3$ & $5 / 6$ & $6 / 6$ \\
15 & 1049 & $7 / 8$ & $3 / 4$ & $7 / 7$ & $7 / 8$ \\
16 & 2722 & $8 / 8$ & $4 / 4$ & $7 / 8$ & $8 / 8$ \\
18 & 736 & $9 / 9$ & $4 / 5$ & $8 / 8$ & $8 / 10^{* *}$ \\
20 & 3220 & $10 / 10$ & $5 / 5$ & $9 / 10$ & $10 / 10$ \\
25 & 5769 & $12 / 13$ & $6 / 7$ & $12 / 12$ & $12 / 13$ \\
\hline
\end{tabular}

Note-Each computer run produced 10 unique series (note exception for series of length 10; see text).

*Only eight series could be obtained meeting the CMIN/CMAX parameters for series of length 10.

**After 50,000 iterations, no series was found in which nine agreements with both single-and double-alternation series occurred.

†Agreements with an alternation series.

$40 \%-60 \%$ was the closest possible to $50 \%-50 \% ; 5,000$ iterations produced only 8 unique series, and an additional 15,000 iterations produced no more. On the other hand, only 105 iterations were required to produce 10 series meeting 30\%-70\% parameters and 84 iterations for 10 series meeting $20 \%-80 \%$ parameters.

Table 1 presents a summary of information on three runs performed per series length on a Burroughs B6700 computer, each of which produced 10 unique series meeting the criteria noted.

A listing of the program and a sample printout are appended. The required input data are entered on one data card, as shown in Table 2.

Table 2

Data Card: Format (1115, F15.10)

\begin{tabular}{clcc}
\hline Cols. & Variable & Cols. & Variable \\
\hline $1-5$ & LS & $31-35$ & RMAX \\
$6-10$ & NSW & $36-40$ & CMIN \\
$11-15$ & ITMAX & $41-45$ & CMAX \\
$16-20$ & NMIN & $46-50$ & HMIN \\
$21-25$ & NMAX & $55-60$ & HMAX \\
$26-30$ & RMIN & $61-75$ & RAND \\
\hline
\end{tabular}

\section{APPENDIX}

B6700 FORTRAN COMPILATION MARK 29.110.005 (UCD)
GELLERMANN
$==\approx==\approx==$

$\begin{array}{ll}C^{*} & \\ C^{*} & \text { PROGRAM FOR FINDING GELLERMANN SERIES OF LENGTH N } \\ \text { C }^{*} & \text { CODED BY R.J. FRAGASZY, UNIV OF CALIFORNIA AT DAVIS, JUL, Y, } 1977 \\ \text { C }^{*} & \\ \text { FILE } & 5=I N, \text { UNIT=READER } \\ \text { FILE } & 6=\text { OUT, UNIT=PRINTER }\end{array}$

\section{INTEGER RMIN,RMAX,CMIN,CMAX,HMIN,HMAX}

$C^{*}$
$C^{*}$
$C^{*}$
$C^{*}$
$C^{*}$
$C^{*}$
$C^{*}$
$C^{*}$

C* $X$ IS THE TEST GELLERMANN SERIES

$C^{*} \quad$ Y IS THE SINGLE ALTERNATION TEST SERIES

$C^{*} \quad$ Z IS THE DOUBLE ALTERNATION TEST SERIES

$C^{*}$ THOSE SERIES MEETING THE CRITERIA ARE STORED IN ARRAY XF

DIMENSION X(40), Y(40), Z(40), XF(50,40)

* INITIALIZE SINGLE AND DOUBLE ALTERNATION ARRAYS

$$
\begin{aligned}
& \text { DO } 1 K=1,40 \\
& Y(K)=0 \\
& 1 Z(K)=0 \\
& \text { DO 2 K }=1,39,2 \\
& 2 Y(K)=1 \\
& \text { DO } 3 K=1,37,4 \\
& 3 Z(K)=1 \\
& D O 4 K=2,38,4 \\
& 4 Z(K)=1
\end{aligned}
$$

C 000:0000:5

C 000:0000:5

$\mathrm{C}$ 000:0000:5

C 000:0000:5

C 00000001 FIB IS 0006 LONG C 00000002 FIB IS 0006 LONG

START OF SEGMENT 002

C 002:0000:0

$\mathrm{C}$ 002:0000:0

C 002:0000:0

$\mathrm{C}$ 002:0000:0

$\mathrm{C}$ 002:0000:0

C 002:0000:0

C 002:0000:0

C 002:0000:0

C 002:0000:0

C 002:0000:0

C 002:0000:0

C 002:0000:0

$\mathrm{C}$ 002:0001:0

C 002:0002:3

C 002:0006:1

C 002:0007:0

C 002:000A:5

$\mathrm{C}$ 002:000C:0

C 002:000F:5

C 002:0011:0 
READ AND WRITE INPUT DATA

$\mathrm{N}=$ LENGTH OF THE SERIES

NSW=NO. OF DIFFERENT SERIES REQUIRED

ITMAX=MAXIMUM NO. OF TRIAL SERIES

NMIN,NMAX=MINIMUM AND MAXIMUM NUMBER OF RIGHTS OR LEFTS PER SERIES

RMIN,RMAX=MINIMUM AND MAXIMUM NUMBER OF REVERSALS PER SERIES

CMIN,CMAX=MINIMUM AND MAXIMUM NUMBER OF AGREEMENTS WITH THE SINGLE OR DOUBLE ALTERNATION TEST SERIES

HMIN,HMAX=MINIMUM AND MAXIMUM NO. OF RIGHTS OR LEFTS IN EACH HALF OF THE SERIES

RAND=SEED FOR THE PSEUDO-RANDOM NUMBER GENERATOR (FORMAT F15.10)

5 READ $(5,1000$, END=9100) N,NSW,ITMAX,NMIN,NMAX,RMIN,RMAX,CMIN,CMAX,

* HMIN,HMAX,RAND

WRITE $(6,1002)$ N,NSW,ITMAX,RAND,NMIN,NMAX,RMIN,RMAX,CMIN,CMAX,

* HMIN,HMAX

$I 1=1$

IF(AMOD(N,2)) $10,20,10$

$20 \mathrm{I} 1=0$

$10 \mathrm{NF}=0$

IT $=0$

$\mathrm{C}^{*}$
$\mathrm{C}^{*}$

INCREMENT COUNTER FOR NO. OF TRIAL SERIES

$200 \mathrm{IT}=\mathrm{IT}+1$

$\mathrm{C}^{*}$

C* IF THE REQUIRED NO. OF SERIES HAS BEEN FOUND OR THE MAXIMUM NO.

$C^{*}$ OF TRIAL SERIES HAS BEEN REACHED, DO NOT GENERATE A NEW SERIES

$\mathrm{C}^{*}$

IF(NF .EQ. NSW .OR. IT .GT. ITMAX) GO TO 9000

$\mathrm{C}^{*}$

$\mathrm{C}^{*} \quad$ INITIALIZE COUNTERS

$\mathrm{C}^{*}$

$\mathrm{L} 1=0$

$\mathrm{L} 2=0$

$\mathrm{L} 3=0$

$\mathrm{L} 4=0$

$\mathrm{L} 5=0$

C* C $^{*}$ GENERATE TERMS FOR THE TRIAL SERIES

C* DO $220 I=1, \mathrm{~N}$

$\mathrm{P}=\mathrm{RANDOM}(\mathrm{RAND})$

IF(P .GT. .5) GO TO 201

$\mathrm{X}(\mathrm{I})=1$

GOTO 202

$201 X(\mathrm{I})=0$

202 IF(I .EQ. 1)GO TO 210

$\mathrm{C}$

C* CHECK TO SEE IF THE (I) TERM IS THE SAME AS THE (I-1) TERM

$\mathrm{C}^{*}$

IF(X(I-1) .EQ. X(I))GO TO 203

$\mathrm{L} 2=\mathrm{L} 2+1$

$\mathrm{L} 1=0$

GOTO 210

$203 \mathrm{~L} 1=\mathrm{L} 1+1$

C* IF FOUR TERMS IN A ROW ARE THE SAME, CHANGE THE LAST TERM

$\mathrm{C}^{*}$

IF(L1 .EQ. 3)GO TO 204

GOTO 210

$204 \mathrm{~L} 2=\mathrm{L} 2+1$

$\mathrm{L} 1=0$

IF(X(I) .EQ. 1)GO TO 205

$\mathrm{X}(\mathrm{I})=1$

GOTO 210

$205 \mathrm{X}(\mathrm{I})=0$

$210 \mathrm{~L} 3=\mathrm{L} 3+\mathrm{X}(\mathrm{I})$

$\mathrm{C}^{*}$

COMPARE WITH SINGLE AND DOUBLE ALTERNATION SERIES, IF THE SAME
C 002:0014:5

C 002:0014:5

$\mathrm{C}$ 002:0014:5

$\mathrm{C}$ 002:0014:5

C 002:0014:5

C 002:0014:5

C 002:0014:5

C 002:0014:5

C 002:0014:5

C 002:0014:5

C 002:0014:5

C 002:0014:5

C 002:0014:5

C 002:0014:5

C 002:0029:2

C 002:0033:0

C 002:0044:4

C 002:004A: 2

C 002:004B:0

C 002:004C: 4

C 002:004D:2

C 002:004E:0

C 002:004E: 4

C 002:004E: 4

C 002:004E: 4

C 002:004E: 4

C 002:0050:0

C 002:0050:0

C 002:0050:0

C 002:0050:0

C 002:0050:0

C 002:0052:2

C 002:0052:2

C 002:0052:2

C 002:0052:2

$\mathrm{C}$ 002:0053:2

C 002:0053:4

C 002:0054:2

C 002:0055:0

C 002:0055:4

C 002:0055:4

C 002:0055:4

C 002:0055:4

C 002:0057:0

C 002:0058:4

C 002:005A:4

C 002:005C: 1

C 002:005C:4

C 002:005E: 1

C 002:005F: 2

C 002:005F:2

C 002:005F:2

C 002:005F:2

C 002:0062:1

C 002:0063:3

C 002:0064: 1

C 002:0064:4

C 002:0066:0

C 002:0066:0

C 002:0066:0

C 002:0066:0

C 002:0067:0

C 002:0067:3

C 002:0068:5

C 002:0069:3

C 002:006B: 2

C 002:006C:5

C 002:006D:2

C 002:006E: 5

C 002:0071:0

C 002:0071:0 
C* THEN INCREMENT THE APPROPRIATE COUNTER

$\mathrm{C}$ 002:0071:0 IF(X(I) .EQ. Y(I)) L4=L4+1

IF(X(I) .EQ. $Z(I)) ~ L 5=L 5+1$

IF(I .NE. (N/2)) GO TO 220

$\mathrm{C}^{*}$
$\mathrm{C}^{*}$
$\mathrm{C}^{*}$
$\mathrm{C}^{*}$

IF THE FIRST HALF OF THE SERIES HAS BEEN GENERATED, CHECK TO SEE IF

IT MEETS THE HMIN, HMAX CRITERIA

IF(L3 .LT. HMIN .OR. L3 .GT. HMAX)GO TO 200

$\mathrm{L} 6=\mathrm{L} 3$

220 CONTINUE

$\mathrm{C}^{*}$

C* TRIAL SERIES HAS BEEN GENERATED, CHECK NMIN, NMAX CRITERIA

$C^{*}$

IF(L3 .LT. NMIN .OR. L3 .GT. NMAX)GO TO 200

$\mathrm{C}^{*}$ CHECK RMIN, RMAX CRITERIA

$\mathrm{C}^{*}$

IF(L2 .LT. RMIN .OR. L2 .GT. RMAX)GO TO 200

C** CHECK CMIN, CMAX CRITERIA

$\mathrm{C}^{*}$

IF(L4 .LT. CMIN .OR. L4 .GT. CMAX .OR. L5 .LT. CMIN .OR. L5 .GT.

* CMAX)GO TO 200

IF(I1 ,EQ. 0)GO TO 230

$\mathrm{L} 7=\mathrm{L} 3-\mathrm{L} 6-\mathrm{X}((\mathrm{L} / 2)+1)$

GO TO 231

$230 \mathrm{~L} 7=\mathrm{L} 3-\mathrm{L} 6$

C

C* CHECK HMIN, HMAX CRITERIA FOR THE SECOND HALF

$\mathrm{C}^{*}$

231 IF(L7 .LT. HMIN .OR. L7 .GT. HMAX)GO TO 200

$C^{*} \quad$ A GOOD SERIES HAS BEEN FOUND, CHECK TO SEE IF IT IS A DUPLICATE

$C^{*} \quad$ OR THE EXACT OPPOSITE OF ONE ALREADY FOUND

$C^{*}$

IF(NF .EQ. 0)GO TO 240

$\mathrm{DO} 236 \mathrm{~K}=1, \mathrm{NF}$

$\mathrm{NA}=0$

DO $235 \mathrm{~L}=1, \mathrm{~N}$

$235 \operatorname{IF}(X(L) . E Q . X F(K, L)) N A=N A+1$

236 IF(NA .EQ. N .OR. NA .EQ. 0)GO TO 200

$\mathrm{C}^{*} \quad$ IF THE SERIES IS A NEW ONE, WRITE IT OUT AND STORE IT IN ARRAY XF

$\mathrm{C}^{*}$

$240 \mathrm{NF}=\mathrm{NF}+1$

WRITE $(6,1003)(X(I), I=1, N)$

DO $250 \mathrm{I}=1, \mathrm{~N}$

$250 \mathrm{XF}(\mathrm{NF}, \mathrm{I})=\mathrm{X}(\mathrm{I})$

GO TO 200

C

C* WRITE NO. OF ITERATIONS, NO. OF SERIES FOUND AND LENGTH OF SERIES

$C^{*}$

9000 WRITE(6,1004) IT, NF, N

$\mathrm{C}^{*}$

C* GO BACK TO READ DATA FOR THE NEXT SEARCH

$\mathrm{C}^{*}$

GOTO 5

1000 FORMAT(11I5,F15.10)

1002 FORMAT(' 1 ','LENGTH OF THE SERIES=’,12,/,'NUMBER OF SERIES DESIRED

*:=', I2,/,'MAXIMUM NUMBER OF TRIAL SERIES=',I5,/,' THE SEED FOR TH

*E PSEUDO-RANDOM NUMBER GENERATOR=',F 13.10,/, MINIMUM NUMBER OF LE

*FTS OR RIGHTS=',I2,/,'MAXIMUM NUMBER OF LEFTS OR RIGHTS=',I2,/,

*'MINIMUM NUMBER OF REVERSALS=',I2,/,' MAXIMUM NUMBER OF REVERSALS

*=',I2,/; MINIMUM NUMBER OF AGREEMENTS=',I2,/; MAXIMUM NUMBER OF

*AGREEMENTS=',I2,/,' MINIMUM NUMBER OF RIGHTS OR LEFTS IN EITHER HA

*LF=',I2,/, MAXIMUM NUMBER OF RIGHTS OR LEFTS IN EITHER HALF=',I2)

1003 FORMAT $(/ /, 40 I 2)$

1004 FORMAT $(, I 6$;' TRIAL SERIES TESTED',/,I3,2X,' GELLERMANN SERIES OF

*LENGTH',I3,1X,'FOUND')

$\mathrm{C}$ 002:0071:0

$\mathrm{C}$ 002:0071:0

$\mathrm{C}$ 002:0075:0

$\mathrm{C}$ 002:0079:0

$\mathrm{C}$ 002:007A:5

$\mathrm{C}$ 002:007A:5

$\mathrm{C}$ 002:007A:5

$\mathrm{C}$ 002:007A:5

C 002:007A:5

C 002:007D: 1

C 002:007E:0

C 002:0080:1

C 002:0080:1

C 002:0080:1

C 002:0080:1

C 002:0082:3

C 002:0082:3

C 002:0082:3

C 002:0082:3

C 002:0084:5

C 002:0084:5

C 002:0084:5

C 002:0084:5

C 002:0088:0

C 002:0089:1

C. 002:008A:2

C 002:008D:5

C 002:008E:2

C 002:008F:5

$\mathrm{C}$ 002:008F:5

C 002:008F:5

C 002:008F:5

C 002:0092:1

C 002:0092:1

C 002:0092:1

C 002:0092:1

C 002:0092:1

C 002:0093:2

C 002:0094:0

C. 002:0094:4

C 002:0096:0

C 002:009D:2

C 002:00A1:4

C 002:00A1:4

C 002:00A : : 4

C 002:00A1:4

C 002:00A3:0

C 002:00AF:2

C 002:00B0:0

C 002:00B5: 4

C 002:00B6:1

C 002:00B6:1

C 002:00B6:1

C 002:00B6:1

C 002:00C0:2

C 002:00C0:2

C 002:00C0:2

C 002:00C0:2

C 002:00C0:5

C 002:00C0:5

C 002:00C0:5

C 002:00C0:5

C 002:00C0:5

C 002:00C0:5

C 002:00C0:5

C 002:00C0:5

C 002:00C0:5

C 002:00C0:5

C 002:00C0:5

C 002:00C0:5 
9100 STOP

$\mathrm{C} 002: 00 \mathrm{C} 0: 5$

END

$\mathrm{C}$ 002:00C1:4

002:00C5:4 IS THE LOCATION FOR EXCEPTIONAL ACTION ON THE 1/O STATEMENT AT 002:0029

SEGMENT 002 IS 00DF LONG

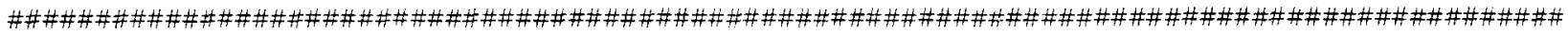

FORMAT SEGMENT IS 008D LONG

START OF SEGMENT 006

NO ERRORS DETECTED. NUMBER OF CARDS $=170$.

SEGMENT 006 IS 000C LONG

COMPILATION TIME $=23$ SECONDS ELAPSED. 2.02 SECONDS PROCESSING $(5050 \mathrm{CPM})$.

D2 STACK SIZE $=6$ WORDS. FILE SIZE $=140$ WORDS. ESTIMATED CORE STORAGE REQUIREMENT $=1335$ WORDS.

TOTAL PROGRAM CODE $=262$ WORDS. ARRAY STORAGE $=888$ WORDS.

NUMBER OF PROGRAM SEGMENTS $=6$. NUMBER OF DISK SEGMENTS $=30$.

PROGRAM CODE FILE = GELLERMANN ON PACK, COMPILER COMPILED ON 09/20/77 (FORTRAN ON PACK)

LENGTH OF THE SERIES $=12$

NUMBER OF SERIES DESIRED $=10$

MAXIMUM NUMBER OF TRIAL SERIES $=5000$

THE SEED FOR THE PSEUDO-RANDOM NUMBER GENERATOR $=0.2431245721$

MINIMUM NUMBER OF LEFTS OR RIGHTS $=6$

MAXIMUM NUMBER OF LEFTS OR RIGHTS $=6$

MINIMUM NUMBER OF REVERSALS $=5$

MAXIMUM NUMBER OF REVERSALS $=6$

MINIMUM NUMBER OF AGREEMENTS $=6$

MAXIMUM NUMBER OF AGREEMENTS $=6$

MINIMUM NUMBER OF RIGHTS OR LEFTS IN EITHER HALF $=3$

MAXIMUM NUMBER OF RIGHTS OR LEFTS IN EITHER HALF $=3$

$\begin{array}{llllllllllll}1 & 0 & 0 & 0 & 1 & 1 & 0 & 1 & 0 & 0 & 1 & 1 \\ 1 & 1 & 1 & 0 & 0 & 0 & 1 & 0 & 0 & 1 & 0 & 1 \\ 0 & 0 & 1 & 1 & 1 & 0 & 0 & 0 & 1 & 1 & 0 & 1 \\ 1 & 1 & 0 & 1 & 0 & 0 & 1 & 1 & 1 & 0 & 0 & 0 \\ 1 & 0 & 1 & 1 & 0 & 0 & 0 & 1 & 1 & 1 & 0 & 0 \\ 1 & 0 & 1 & 0 & 0 & 1 & 0 & 0 & 0 & 1 & 1 & 1 \\ 1 & 1 & 1 & 0 & 0 & 0 & 1 & 1 & 0 & 1 & 0 & 0 \\ 1 & 0 & 0 & 1 & 1 & 0 & 0 & 1 & 1 & 0 & 0 & 1 \\ 0 & 0 & 1 & 1 & 0 & 1 & 1 & 0 & 1 & 1 & 0 & 0 \\ 1 & 1 & 0 & 0 & 1 & 0 & 1 & 1 & 0 & 0 & 0 & 1\end{array}$

1494 TRIAL SERIES TESTED

10 GELLERMANN SERIES OF LENGTH 12 FOUND

LENGTH OF THE SERIES $=12$

NUMBER OF SERIES DESIRED $=10$

MAXIMUM NUMBER OF TRIAL SERIES $=5000$

THE SEED FOR THE PSEUDO-RANDOM NUMBER GENERATOR $=0.3520784129$

MINIMUM NUMBER OF LEFTS OR RIGHTS $=6$

MAXIMUM NUMBER OF LEFTS OR RIGHTS $=6$

MINIMUM NUMBER OF REVER SALS $=5$

MAXIMUM NUMBER OF REVERSALS $=6$

MINIMUM NUMBER OF AGREEMENTS $=6$

MAXIMUM NUMBER OF AGREEMENTS $=6$

MINIMUM NUMBER OF RIGHTS OR LEFTS IN EITHER HALF=3

MAXIMUM NUMBER OF RIGHTS OR LEFTS IN EITHER HALF $=3$

$\begin{array}{llllllllllll}0 & 1 & 1 & 1 & 0 & 0 & 1 & 0 & 1 & 1 & 0 & 0 \\ 1 & 1 & 1 & 0 & 0 & 0 & 1 & 1 & 0 & 1 & 0 & 0 \\ 1 & 1 & 1 & 0 & 0 & 0 & 1 & 0 & 0 & 1 & 0 & 1 \\ 1 & 1 & 0 & 0 & 1 & 0 & 1 & 1 & 0 & 0 & 0 & 1 \\ 1 & 0 & 1 & 0 & 0 & 1 & 0 & 0 & 0 & 1 & 1 & 1 \\ 0 & 0 & 1 & 1 & 1 & 0 & 0 & 0 & 1 & 1 & 0 & 1 \\ 1 & 0 & 0 & 1 & 1 & 0 & 0 & 1 & 1 & 0 & 0 & 1 \\ 0 & 0 & 1 & 0 & 1 & 1 & 0 & 0 & 0 & 1 & 1 & 1 \\ 1 & 0 & 1 & 1 & 0 & 0 & 0 & 1 & 1 & 1 & 0 & 0 \\ 1 & 1 & 0 & 0 & 1 & 0 & 0 & 1 & 0 & 0 & 1 & 1\end{array}$


LENGTH OF THE SERIES $=12$

NUMBER OF SERIES DESIRED $=10$

MAXIMUM NUMBER OF TRIAL SERIES $=5000$

THE SEED FOR THE PSEUDO-RANDOM NUMBER GENERATOR $=0.9502147427$

MINIMUM NUMBER OF LEFTS OR RIGHTS $=6$

MAXIMUM NUMBER OF LEFTS OR RIGHTS $=6$

MINIMUM NUMBER OF REVERSALS $=6$

MAXIMUM NUMBER OF REVERSALS $=6$

MINIMUM NUMBER OF AGREEMENTS $=6$

MAXIMUM NUMBER OF AGREEMENTS $=6$

MINIMUM NUMBER OF RIGHTS OR LEFTS IN EITHER HALF $=3$

MAXIMUM NUMBER OF RIGHTS OR LEFTS IN EITHER HALF $=3$

$\begin{array}{llllllllllll}1 & 0 & 1 & 1 & 0 & 0 & 0 & 1 & 1 & 1 & 0 & 0 \\ 1 & 1 & 1 & 0 & 0 & 0 & 1 & 0 & 0 & 1 & 0 & 1 \\ 0 & 0 & 0 & 1 & 1 & 1 & 0 & 0 & 1 & 0 & 1 & 1 \\ 0 & 1 & 1 & 0 & 0 & 1 & 1 & 0 & 0 & 1 & 1 & 0 \\ 0 & 1 & 0 & 1 & 1 & 0 & 1 & 1 & 1 & 0 & 0 & 0 \\ 1 & 0 & 0 & 0 & 1 & 1 & 0 & 1 & 0 & 0 & 1 & 1 \\ 1 & 1 & 0 & 0 & 0 & 1 & 1 & 1 & 0 & 0 & 1 & 0 \\ 0 & 0 & 1 & 0 & 1 & 1 & 0 & 0 & 0 & 1 & 1 & 1 \\ 1 & 1 & 0 & 0 & 1 & 0 & 1 & 1 & 0 & 0 & 0 & 1 \\ 5001 \\ 9 \\ 9\end{array}$

\section{REFERENCES}

Gellermann, L. W. Chance orders of alternating stimuli in visual discrimination experiments. Journal of Genetic Psychology, 1933, 42, 206-208.
Hilgard, E. R. Methods and procedures in the study of learning. In S. S. Stevens (Ed.), Handbook of experimental psychology. New York: Wiley, 1951. Pp. 517-567.

(Accepted for publication December 16, 1977.) 